\title{
FROM FOCUS ON SOUNDS TO FOCUS ON WORDS IN ENGLISH PRONUNCIATION INSTRUCTION
}

\author{
JOLANTA SZPYRA-KOZLOWSKA \\ jszpyra@klio.umcs.lublin \\ SLAWOMIR STASIAK \\ Maria Curie-Sklodowska University
}

\begin{abstract}
The paper addresses a very important aspect of Polish-accented English, namely the issue of frequent phonetic errors made by Polish learners which do not result from their inability to produce foreign sounds correctly, but which stem from various interference factors (e.g foreign pronounced as [fo'rejn]). Following Szpyra-Kozłowska's (in press a) claims that such errors hinder successful communication far more than other segmental and suprasegmental inaccuracies and should thus be treated as a top pedagogical priority, what is suggested is a shift in phonetic instruction from the focus on the production of sounds and prosodies to the focus on the pronunciation of problematic words. Our major goal is to demonstrate how this proposal can be implemented in the language classroom.

The authors present a report on the experiment in which a group of 25 Polish secondary school pupils has undergone a special training in the pronunciation of 50 commonly mispronounced words with the use of special, teacher-designed materials. The effectiveness of the employed procedure as well as the pupils' reactions to it are examined and pedagogical conclusions are drawn.
\end{abstract}

Key words: English pronunciation/phonetics, phonetically difficult words, phonetic priorities, teaching English pronunciation

\section{Introductory remarks}

Szpyra-Kozłowska (in press a and b) argues that the traditional focus of pronunciation instruction on segments and prosodies fails to address the issue of phonetically deviant words, known as local errors, which abound in foreign-accented English.

For instance, Polish learners of English frequently mispronounce the name Disney as [d'isnej], even though the form [dizni] does not contain any particularly difficult sounds ${ }^{1}$ and sound combinations. Clearly, the Polish English version is spelling-based and follows Polish spelling-to-pronunciation rules according to which the $<$ sn $>$ sequence is

\footnotetext{
${ }^{1}$ It should be added that all consonants in this word in Polish have the dental rather than the alveolar place of articulation.
} 
pronounced as [sn] and <ey> as [ej]. ${ }^{2}$ Needless to say, all consonants and vowels are replaced with their Polish equivalents, with an additional palatalization of the initial plosive by what is taken to be a fully front [i] vowel.

In Szpyra-Kozłowska (in press) it is demonstrated that such and similar mispronunciations are found not only in Polish English, but also in other interlanguages, which points to a more general importance of the issue under discussion. We have also proved experimentally that errors of this kind are detrimental to successful communication as they make utterances which contain them difficult to understand. Moreover, they create the effect of a heavy foreign accent and are irritating for many native English listeners. In fact, we have shown that the consequences of local errors are frequently more serious than in the case of global segmental and suprasegmental inaccuracies. The conclusion has been that such seriously mispronounced words should constitute a top pedagogical priority.

In this paper we would like to advance a claim that, if we take the results of such error gravity studies seriously, then eliminating phonologically deviant words from learners' English should be the primary concern of language instructors. We would also like to take a step further and suggest the need for a complete shift of focus from the traditional teaching of segments and prosodies to training in the pronunciation of whole words. ${ }^{3}$ In what follows, however, we will confine ourselves to the problem of local errors and effective ways of eliminating them from learners' English.

The issue is nontrivial and acquires paramount importance in the case of numerous people who study or work abroad, businessmen involved in international operations, scholars attending international conferences, etc., in whose case what matters is acquiring effective skills of communication via spoken English, often at the cost of a lower quality of various language components, including phonetic accuracy. In such instances eliminating local errors is vital if the comprehensibility and intelligibility of the foreign speaker's English are to be achieved.

It is evident that in the case of mispronunciations under discussion, phonetic training restricted to segments and suprasegments is insufficient and incapable of removing them. Simply, the problem does not concern learners' inability to articulate certain sounds properly, but their lack of awareness that the segmental and sometimes prosodic makeup of the problematic items is different from the one stored in their phonetic memory. In other words, even if the mastery of individual sounds, usually practiced in simple monosyllabic words or minimal pairs, is achieved, this will not automatically lead to the

\footnotetext{
${ }^{2}$ As a matter of fact, <ey> should be pronounced as a sequence of two vowels [e] and [y], but since such a combination does not occur in Polish, the final letter is interpreted as the palatal glide.

3 Obviously, sounds are not practiced in isolation, but in words and phrases. The problem is, however, that once the focus of instruction is on sounds and sound contrasts, the words selected for practice are of secondary importance and serve only as a context for the occurrence of particular segments. To put it differently, lexical items are grouped according to the specific sounds, i.e. a vowel or a consonant, they contain and not depending on the degree of phonetic difficulty they pose for learners. A semantic grouping of words for phonetic training, suggested for example in some tasks proposed by Hewings (2004) is a step in the right direction, but it cannot be viewed as fully effective as such sets, in terms of pronunciation, include both easy and difficult items.
} 
correct production of the incorrectly remembered words. Instruction devoted to teaching learners the major spelling-to-pronunciation rules is not effective in such instances either since it is exactly their overgeneralization that is a frequent source of the errors in question.

It should be pointed out that current English pronunciation teaching materials generally fail to address this problem. They focus almost entirely on sounds, sound combinations and suprasegmental issues. This is true both of older classics (e.g. Ponsonby 1982) as well as of more recent sources (e.g. Kelly 2000). Thus, typically (e.g. Kelly 2000), we can find there sections devoted to vowels, consonants, sometimes difficult consonant clusters, word and sentence stress, intonation, rhythm and changes occurring in connected speech. Occasionally some spelling-to-pronunciation rules are discussed. The question of phonetically problematic words is generally ignored though some authors propose exercises concerning certain types of vocabulary they consider difficult for learners. Hewings (2004) should be singled out since he offers several tasks which involve the pronunciation of some first names, place names, products, planets, nationality words, etc. Of Polish sources Sobkowiak (1996) deserves a special mention with the list of about 700 'words commonly mispronounced.' Interestingly, although the list is placed in the appendix and thus is marginalized in the book, it belongs, as is often admitted, to the most frequently used parts of it. This proves many teachers' intuition concerning the importance of local errors.

The conclusion is evident; in order to reduce/eliminate such errors, pronunciation instructors cannot rely on the existing publications but should produce their own phonetic materials suited to the specific needs of their learners. The reduction of such errors is not an easy task since they are often fossilized and reinforced by the fact of their high frequency in learners' English.

\section{The experiment}

In this section we present a report on an experiment whose goal has been to implement the conclusions formulated earlier. Namely, an attempt has been made to teach a group of Polish learners a set of 50 commonly mispronounced words using various activities and teacher-constructed materials. Then the effectiveness of this procedure and the learners' responses to the devised phonetic training were examined.

\subsection{Diagnostic material}

The diagnostic material consisted of 10 sentences with 50 commonly mispronounced words. A list of about 500 such items has been collected by one of the authors, Sławomir Stasiak, who noted down the most common errors made by his pupils. The diagnostic sentences with the test words are provided in Appendix 1. Below we present the problematic items transcribed in their Polish English versions. The employed vocabulary represents an intermediate level of lexical difficulty.

It should be noted that the experimental items are mispronounced by Polish learners in a variety of ways, only some of which are reflected in the provided transcriptions. The 
erroneous versions differ from each other in terms of the types of departures from the phonetically correct forms. Thus, although in most of them some segments (usually vowels) are replaced with phonetically rather distant sounds (e.g. [e] in sweat by Polish [i], i.e. [sw'it]), in some cases the learners' realizations depart from the original less drastically (e.g. the diphthong in don't is mispronounced as the Polish monophthong [o]). It is also worth pointing out that the list below includes some proper names frequently pronounced incorrectly by Poles, like Turner, Murphy or Presley.

\begin{abstract}
dead [d'it], said [sejt], opposite ['opozait], examine ['egzemajn], their [dej], soup [sowp], steak [st'ik], lettuce ['let'jus], vegetables [vedže'tejbls], saw [sow], near [ńir], meadow ['m'idow], capable [ke'pejbl], guinea [gwi'nea] pig, sweat [sw'it], foreign [fo'rejn], don't [dont], climate [klajmejt], colonel [ko'lonel], captain ['keptejn], work [work], radar [radar], certificate [ser't'if'ikejt], preface [pre'fejs], author ['awtor], butcher ['bačer], lawyer ['lajer] nurse [nars], favourite ['fever'it], ancient ['enšent], says [seis], comfortable [komfor'tejbl], castle [kastel], mountains [mowtajns], walk [wolk], damaged [de'mejčt], surface ['serfejs], dangerous ['dendžerows], wolf [wolf], occur [o'kjur], instead [in'st'it], Turkey [tark'i], separate (adj.) ['sep(e)rejt], journey ['džurnej], country ['kawntri], Elvis Presley ['preslej], Barbara Streisand ['strejsant], Tina Turner ['tarner], Eddie Murphy ['marf'i], Leonard ['lionart]
\end{abstract}

\title{
2.2. Subjects
}

The subjects in this experiment were a group of 25 pupils, aged 17, attending an upper secondary school in Stalowa Wola and taught English by one of the authors. ${ }^{4}$ They represent the pre-intermediate to intermediate level of general proficiency in English. Their pronunciation is poor due to an almost complete negligence of phonetic training prior to the experiment. Out of the whole class 5 pupils (4 boys and one girl) with very poor pronunciation have been selected by the teacher for the recordings.

\subsection{Pre-test}

In September 2009 the selected 5 pupils were individually recorded having been asked to read the diagnostic sentences. This procedure has yielded 250 tokens whose pronunciation was subsequently examined for the presence of the errors discussed in the previous section.

\subsection{Phonetic training}

The phonetic training of the experimental class lasted for about 8 weeks during regular English lessons, i.e. twice a week, in which pupils were given extra phonetic exercises. During the first period emphasis was placed on the introduction of phonetic symbols and

\footnotetext{
${ }^{4}$ S. Stasiak.
} 
various transcription exercises while in the second part of training the focus was on practising the test items. About 10 minutes of each lesson were devoted to this issue.

The following types of tasks and activities were employed: ${ }^{5}$

1. Traditional 'listen and repeat' exercises - the pupils listened to the test items and phrases which contained them pronounced by the teacher and repeated them chorally and individually.

2. Phonetic transcription exercises - the pupils learned the phonetic symbols, looked up the test items in a pronunciation dictionary, copied them and repeated.

3. Raising phonetic awareness exercises designed by the authors (finding those items in the provided set of words which share a particular segment, identifying rhyming words and homophones, indicating words with silent letters, discussing mismatches between spelling and pronunciation),

4. Production exercises designed by the authors.

According to the teacher who carried out the phonetic training described here, its initial phase in which the basics of phonetic transcription were introduced and 'listen and repeat' activities were employed was rather tedious and not very attractive for the learners. However, the use of other tasks presented above produced very positive reactions on their part. The pupils apparently enjoyed putting the newly acquired skills into practice and engaged very actively and even enthusiastically in new activities. With every correctly produced difficult word their phonetic confidence seemed to grow.

\subsection{Post-test}

After 2 months of additional phonetic training involving the problematic items 5 subjects selected at the beginning of the experiment were asked to record the diagnostic sentences again. It should be added that they were not included in the exercises administered to the class in the course of their training.

\subsection{Questionnaire}

In the final stage of the experiment all the participants were asked to complete a questionnaire in which they were asked to evaluate the effectiveness of the phonetic training they had undergone.

\subsection{Results}

The graph below presents the results of the pre-test and post-test, where the terms 'correct' and 'incorrect' do not refer to phonetic details (such as the exact place of articulation of consonants or the exact quality of vowels), but the presence and absence of considerable departures from the original English phonemic structure of the tested items.

\footnotetext{
${ }^{5}$ Representative examples of tasks used in the training are provided in Appendix 2.
} 


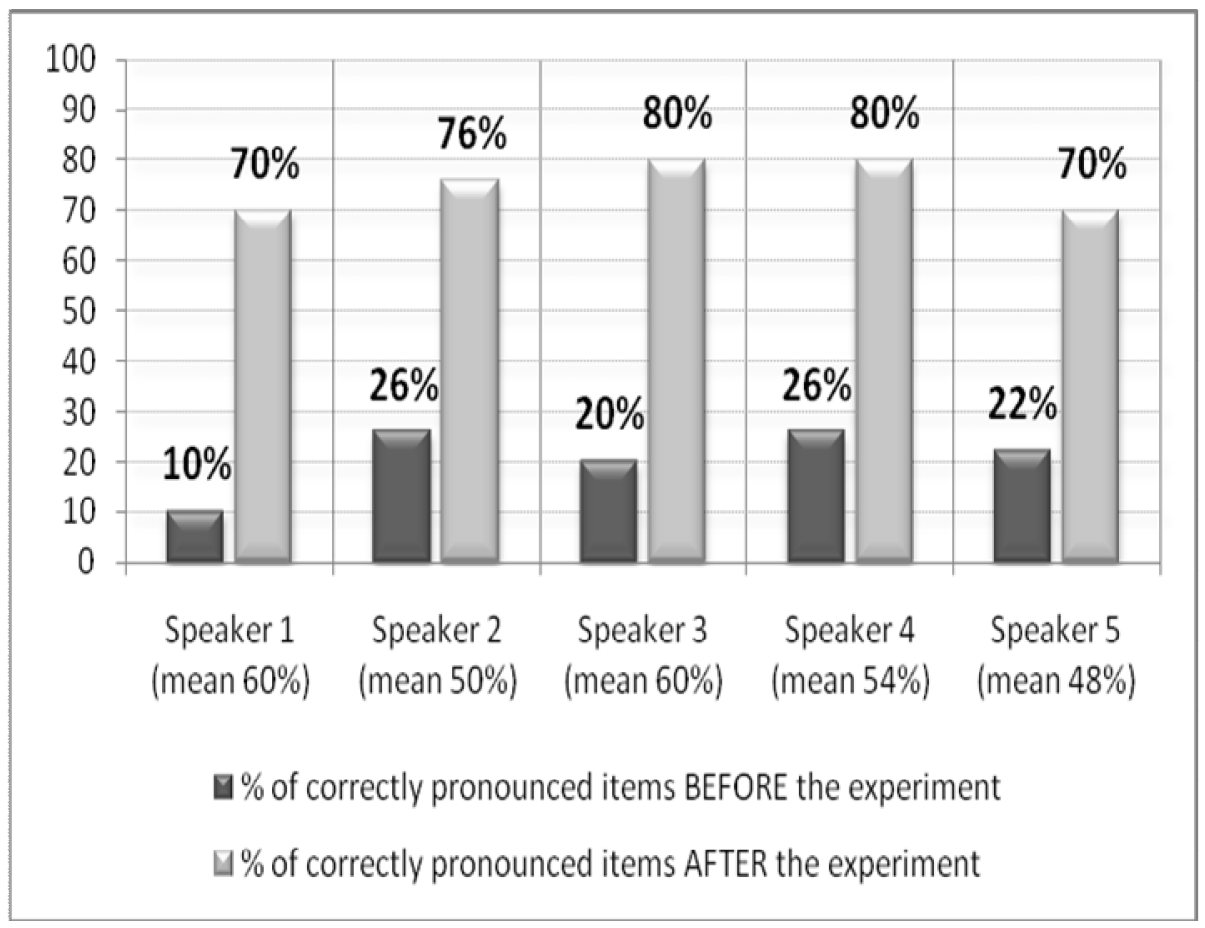

Graph 1. Results of the pre-test and post-test

The pretest results show that out of 250 obtained tokens, only 52, i.e. $20,8 \%$, were pronounced correctly by the participants, which supports our observations concerning the phonetic difficulty of the tested items. The post-test data indicate that the training was effective in that all the subjects made a marked progress, from $25 \%$ to $60 \%$, with the mean of $54.4 \%$. This means 188 correctly pronounced items in the second recording. Evidently, the correction of local errors is teachable. It should be pointed out that only pupils with very poor pronunciation were selected for the experiment. In the case of learners with a higher phonetic aptitude the results were even better. ${ }^{6}$

Let us now examine the pronunciation of which the tested words turned out easy and difficult to improve.

\section{Radical \& marked improvement:}

guinea pig, said, Turner, Leonard, instead (all subjects)

steak, lettuce, vegetables, foreign, colonel, radar, certificate, preface, Presley, comfortable, mountains, surface, occur, Turkey (4 subjects)

\footnotetext{
${ }^{6}$ This conclusion is based on the experimenter's observations as no formal measurements of better pupils' progress in the pronunciation of the tested items have been made.
} 
Negligible \& no improvement:

near, don't, tourists, ancient

saw, says, country

A generalization which can be drawn is that the greater, the most striking the difference between the correct pronunciation and the learners' version, the easier it is to eliminate the error. Simply, once such mispronunciations are pointed out to the pupils and juxtaposed with the proper form, the incorrectness of the former becomes so conspicuous that it strengthens the motivation to eliminate them. Thus, in the case of the first set of words, which tended to be grossly distorted by the learners, either radical or marked improvement has been noted.

Of course the opposite is also true. The items in the second group are characterized by the departure from the correct version either through the replacement of a diphthong with a perceptually similar monophthong ${ }^{7}$ (e.g. near, don't) or by an opposite change from a monophthong to a diphthong (e.g. saw, country). While the latter phenomenon can be attributed to the powerful influence of spelling, the former also results from a Polish tendency to monophthongize many English diphthongs (centring diphthongs in particular), as evidenced in the phonological adaptation of the following English loan words:

$$
\text { E goal > P gol [gol] E drain > P dren [dren] E fair }>\text { fair }[\text { fer }]
$$

Mispronunciations of the words in the second set are particularly persistent and difficult to eradicate since the correct and incorrect versions appear to be perceptually rather similar to the Polish learners who are therefore not sufficiently motivated to improve their pronunciation. Simply, errors of this type are not perceived by them as serious enough to require any modifications. ${ }^{8}$

\subsection{Questionnaire results}

After the post-test recordings, all 25 participants were asked to provide anonymous answers to three questions which are presented below. ${ }^{9}$

Question 1. Has, according to you, your English pronunciation improved for the last two months?

The pupils had three options to choose from: yes, no and I don't know. All of them $(100 \%)$ selected the first answer, which means that in the participants' subjective opinion the applied phonetic training resulted in their phonetic progress.

Question 2. What aspects of English pronunciation have you learnt in particular?

In this case the pupils claimed that they learnt how to articulate correctly various frequent words which they used to mispronounce. They reported that they had started

\footnotetext{
${ }^{7}$ We mean here perceptual similarity for Polish learners.

${ }^{8}$ It should be added that this explanation is not applicable to all the test items. Thus, for example, all the subjects learnt to pronounce correctly the word instead, but not dead, Turner, but not Murphy. It is not clear why such differences have occurred.

${ }^{9}$ Both the questions and answers were in Polish. Here we present our translations.
} 
paying more attention to the relationship between English spelling and pronunciation and claimed that, due to the use of phonetic symbols and phonetic transcription, they learnt how to look up the pronunciation of new words in dictionaries.

Question 3. Which type(s) of phonetic exercises used in the course of the training do you consider particularly useful?

The majority of pupils were of the opinion that exercises involving the phonetic script were particularly useful to them since by recording various words by means of transcription symbols in the notebooks, it was easier to remember their pronunciation and avoid spelling-based realizations. They also appreciated being able to use pronouncing dictionaries on their own. It should be added that many phonetic awareness tasks designed by the authors (see the appendix) were carried out with the help of dictionaries. The learners also evaluated highly traditional 'listen-and-repeat' exercises.

Also in the teacher's view the use of the phonetic script, apart from production activities, turned out to be the most important factor in improving the pupils' pronunciation. It made them realize the extent of their phonetic errors and taught them how to be more independent from the teacher in learning the pronunciation of new words. In his opinion, the greatest success of the experiment lies not only in reducing the number of mispronounced words, but also in raising the pupils' phonetic awareness and boosting up their phonetic confidence by convincing them that improvement in their English pronunciation can be achieved.

\section{Conclusion}

In this paper we have suggested that phonetic instruction should, first and foremost, focus not on segments and suprasegments, but on the pronunciation of whole words, particularly those ones whose distortion might lead to communicative problems. This shift of emphasis appears to have the following advantages:

- Learning to pronounce whole words without major phonological deviations is easier than achieving the mastery of individual segments and prosodic features, as proved by the experiment we have carried out in the course of which very little segmental and prosodic progress could be observed, with, however, striking improvement in the elimination of the errors in test items.

- Mastering individual sounds and sound contrasts does not necessarily lead to the improvement in the production of problematic words since the mispronounced forms are not the result of articulatory difficulty, but stem from the incorrect storage of these items in learners' phonetic memory.

- The suggested procedure is more rewarding for the learner as it results in immediate communicative gains and the feeling of accomplishment which is difficult to achieve in the training of segments and suprasegmentals.

- These goals can be achieved if additional tasks and exercises are employed which are specifically designed for problematic items. They should involve the use of phonetic transcription, language awareness tasks as well as production exercises. 


\section{References}

Hewings, M. 2004. Pronunciation Practice Activities. Cambridge: Cambridge University Press.

Kelly, G. 2000. How to Teach Pronunciation. Pearson Education.

Kenworthy, J. 1987. Teaching English Pronunciation. London \& New York: Longman.

Ponsonby, M. 1998. How Now Brown Cow? A Course in the Pronunciation of English. Hemel Hempstead: Prentice Hall Europe ELT.

Sobkowiak, W. 1996. English Phonetics for Poles. Poznań: Bene Nati.

Szpyra-Kozłowska, J. (in press a). On the irrelevance of sounds and prosody in foreignaccented English.

Szpyra-Kozłowska, J. (in press b). Phonetically difficult words in intermediate learners' English. 


\section{Appendix 1}

A list of diagnostic sentences used in the experiment

1. They had soup [sowp], then steak [st'ik] with lettuce [letjus] and other vegetables [veje'tejbls] for dinner.

2. They saw [sow] a dead [d'it] guinea [gwinea] pig in the meadow [m'idow] near [ńir] the house opposite ['opozait] ours.

3. Foreign [fo'rejn] tourists don't [don't] like the climate [klajmejt] here.

4. A colonel [ko'lonel] and a captain ['keptejn] worked [workt] on a radar [radar].

5. They examined ['egzemajnt] his certificate [ser't'if'ikejt] and said [sejt] he wasn't capable [ke'pejbl] of writing the preface [pre'fejs] to this author's [awtors] book.

6. In this family one brother is a butcher [bačer], another is a lawyer [lajer] and their [dej] sister is a nurse [nars].

7. Her favourite ['fever'it] stars are Elvis Presley [preslej], Barbara Streisand [strejsant], Tina Turner [tarner] and Eddie Murphy [marf'I].

8. He says [seis] it isn't comfortable [komfor'tejbl] to live in this ancient [enšent] castle [kastel] in the mountains [mowtajns] and walk [wolk] across that damaged [de'mejčt] bridge every day.

9. Leonard ['lionart] felt sweat [sw'it] on the surface ['serfejs] of all his body when he saw that dangerous ['denjerows] wolf [wolf].

10. It occurred [o'kjuert] that instead [in'st;it] of going to Turkey [tark'i], we had to go on separate ['sep(e)rejt] journey [jurnej] to another country [kawntry]. 


\section{Appendix 2. Selected types of tasks used in the phonetic training.}

I. In the set below find those words which are pronounced with the sound [ei] (as in take):

surface climate ancient favourite steak climate captain radar

said certificate dangerous comfortable foreign Presley damaged preface

II. In the set below find those words which are pronounced with the sound [ai] (as in my):

opposite examined mountains Streisand climate said captain

III. In the set below indicate those words which rhyme with bed:

instead sweat said dead bead mead head meat

IV. What vowel do the following words share?

Turner Murphy nurse worked journey Turkey colonel

V. What vowel do the following words share?

guinea pig foreign opposite Presley favourite

VI. Which consonant is not pronounced in the words below?

colonel worked castle walk journey

VII. Below pairs of words are given. Decide whether the underlined parts are pronounced in the same way or differently:

3. saw - more

4. preface-face-

5. author - draw -

6. Leonard-sweat

7. surface-preface -

8. walk-lawyer -

9. don't-meadow

10. $b \underline{\underline{u}} t c h e r-s h \underline{\underline{u}} t-$

11. nü rse - journey

12. $\underline{\text { radar }- \text { author }-}$

VIII. Analyse the words given below:

soup steak lettuce preface saw dead opposite mountains their country

dangerous castle Turkey certificate author occurred says worked Turner

IX. Now complete the following tasks:

1. Enumerate those words which contain the vowel [ei] (as in take)

2. Enumerate those words which contain the vowel [e] (as in get): 
3. Enumerate those words which are pronounced with the final voiced consonant:

4. Enumerate those words which contain the vowel [3:] (as in girl):

5. Enumerate those words which contain the vowel [av] (as in now)

IX. Answer the following questions orally:

1. What is your favourite soup? My favourite soup is

2. What are your favourite vegetables? My favourite vegetables are

3. What does a lawyer do? A lawyer

4. What does a butcher do? A butcher

5. What does a nurse do? A nurse

6. Who is Tina Turner? Tina Turner

7. Who is Eddie Murphy? Eddie Murphy

8. Who is Barbara Streisand? Barbara Streisand

9. Who was Elvis Presley? Elvis Presley

10. What can a radar be used for? A radar

$\mathrm{X}$. Read the following sentences aloud and say whether they are true or not using whole sentences.

1. A wolf is a dangerous animal. I think that a wolf

2. Turkey is in Africa. I think Turkey

3. Leonard is a female name. I think Leonard

4. A colonel is a soldier. I think a colonel

5. A guinea pig has long hair. I think a guinea pig

6. Zakopane is in the mountains. I think

7. A captain is higher in rank than a major. I think a captain

8. Tulips don't grow in the meadow. I think

9. Poland is a bigger country than France. I think

10. Beefsteak is made of cow's meat. I think beefsteak 